\title{
Thermal Emission by Using Different Light Sources Unit which Used in Den- tistry
}

Mona Y Shamon

BDS, MSc (Assis Lec.)
Department of Dental Basic Science

College of Dentistry, University of Mosul

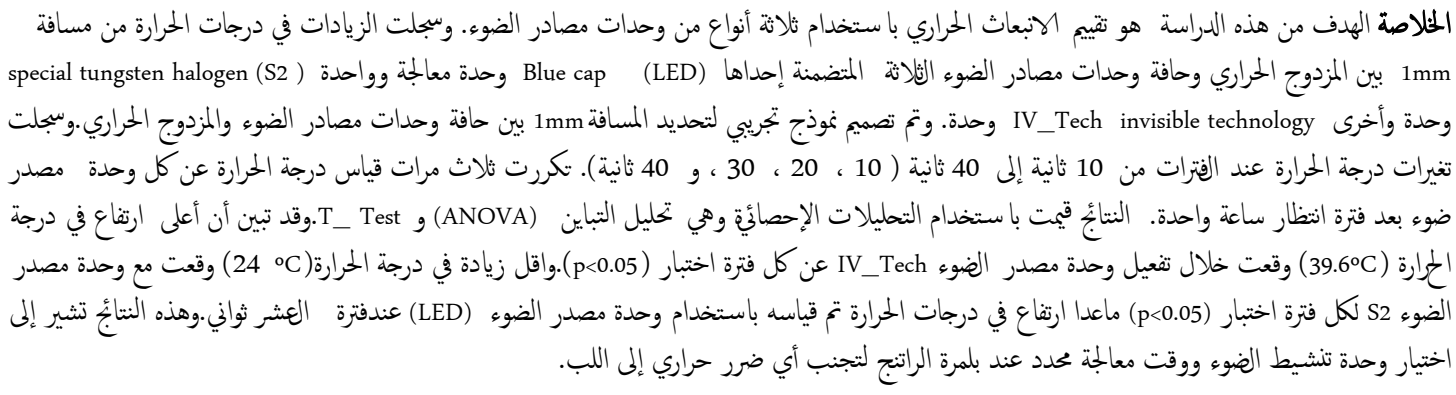

\section{ABSTRACT}

Aim: To evaluate the thermal emission by three types of light sources units. Materials and methods: Temperature were recorded from distance of $1 \mathrm{~mm}$ from a thermocouple the tip of three different types of light sources units including one Blue cap (LED) source unit, one special tungsten halogen $\left(\mathrm{S}_{2}\right)$ source unit, and one invisible technology (IV_ Tech) source unit. Temperature changes were recorded in 10 second intervals up to 40 seconds $(10,20,30$, and 40 seconds). Temperature measurements were repeated three times for every light source unit after a one hour standby period. Mean values were compared statistically with Chi-Square test to determine the significant difference among the tested groups at $(\mathrm{p}<0.05)$ level of significance. Results: The highest temperature rises $\left(39.6^{\circ} \mathrm{C}\right)$ occurred during activation of an $\mathrm{IV}_{-}$Tech light source unit for every test period. The least temperature increase ( 24 ${ }^{\circ} \mathrm{C}$ ) occurred with a LED light source unit for each tested period. Conclusions: These results indicated that the choice of light activation unit and curing time is important during the light activated polymerization of composite resins to avoid any thermal damage to the pulp.

Keywords: Dentistry, light source unit، thermal emission.

Shamon MY. Thermal Emission by Using Different Light Sources Unit which Used in Dentistry. $A l-$ Rafidain Dent J. 2010; 10(2):309-313.

Received: 29/4/2009 Sent to Referees: 29/4/2009

Accepted for Publication:28/6/2009

\section{INTRODUCTION}

There are several reasons to study a problem of thermal stimuli propagation in dental structures. Heat effects and heat transfer phenomena are of a great importance in dentistry. Firstly, the analysis of the temperature distribution could substantially help to diagnose many diseases (The use of thermo vision technique for diagnosis of periodontal diseases) (1). Secondly, the temperature and temperature-related effects are major risk factors in destruction of tooth structures. The last concerns both hard and soft tooth tissues and, in addition, the treated tooth with dental filling structures. The thermal loads are responsible for that ${ }^{(2)}$. Light source of adequate inten- sity and wavelength from 400-500nm is required for polymerization to activate light sensitive restorative materials, with maximum absorption at $468 \mathrm{~nm}$. Visible light in the blue region of the spectrum has gained popularity over ultraviolet light because of its ability to produce a greater depth of polymerization and to avoid possible eye damage. A 400-500 nm band pass filter is used to remove undesired wavelengths from the white halogen source, resulting in the typical blue light of the dental curing unit ${ }^{(3)}$.Temperature rise during curing of light activated restoratives, relates both to the polymerization exothermal of the material and also to the thermal emission from the dental light cur- 
ing unit . Since curing times up to $40 \mathrm{sec}$ are often required to cure the composites to an adequate depth, high intensity halogen lamps in the 400-500nm range which exceeds $1000 \mathrm{mw} / \mathrm{cm}^{2}$ have been introduced resulting in curing times of about 10 sec. The use of high-intensity lamps reduces the curing time, but also increases the risk of pulped damage ${ }^{(4)}$.Temperature rise of $5.5^{\circ} \mathrm{C}$ within the pulp chamber would lead to irreversible pulp damage ${ }^{(5,6)}$.

Halogen bulbs generate light by electrical heating of a tungsten filament to extremely high temperatures. Most heat radiation, which is in infrared of the electromagnetic spectrum, is generated and only a small percent of the light output desired for polymerization is in the visible spectrum $^{(7)}$. These spectral impurities induce heating of the tooth and composite during the curing process. The high operating temperatures and large quantity of heat are produced during the curing cycles and degrade the bulb and reflector, reducing the curing effectiveness over time. To overcome these problems inherited with halogen lights, new devices based on solidstate light emitting diode (LED) technology have been developed. They use a junctions of doped semiconductors ( $p-n$ junctions) for the generation of light ${ }^{(8,9)}$.

Light curing units can cause a temperature increase that could lead to irreversible pulped damage ${ }^{(10-13))}$.The potential damaging effect of temperature increase on pulp tissue during restorative treatment is a major concern in the field of dentistry for many years. Thermal transfer to pulp is influenced by material shade, thickness, composition, porosity, curing time and residual dentin thickness. Temperature rise during the curing of restorative materials is however mainly contributed by the light source. It also varies with the type of curing unit, quality of light filter, output intensity and irradiation time ${ }^{(14,15)}$.

The purpose of this in vitro study was to monitor temperature rises on the exit window of the three different light guides every ten second, during a 40 second period; using three different types of light curing units. The hypothesis is the existence of a difference in temperature rise during the activation of three types of curing units due to the different levels of energy emitted by the units.

\section{METHODS AND MATERIALS}

Three types of light sources units( Table 1)including the following:

1. Blue cap (LED) light source unit at $1000 \mathrm{mw} / \mathrm{cm}^{2}$ (DxM Co.,

$$
\text { Ltd, Taiwan) }
$$

2. Special tungsten halogen $\left(\mathrm{S}_{2}\right)$ light source unit at $1600 \mathrm{mw} / \mathrm{cm}^{2}$ (HANGZHOU ZHONGRUM. China Medical Instrument)

3. Invisible technology (IV_ Tech) light source unit at $1800 \mathrm{mw} / \mathrm{cm}^{2}$

( Benlioglu Dental, Turkey)

Table (1): Tested light sources units.

\begin{tabular}{|c|c|c|c|}
\hline Light sources units & $\begin{array}{c}\text { Light Intensity } \\
\left(\mathbf{m w} / \mathbf{c m}^{\mathbf{2}}\right)\end{array}$ & Diameter of Tip (mm) & Manufacturer \\
\hline Special tungsten halogen (S2) & 1600 & 8 & HZ. . China \\
\hline $\begin{array}{c}\text { Invisible technology } \\
\text { (IV_Tech) }\end{array}$ & 1800 & 11 & Benlioglu ,Turkey \\
\hline Blue cap (LED) & 1000 & 10 & DxM Co., Ltd Taiwan \\
\hline
\end{tabular}

An experimental model was designed to fix the distance between the thermocouple and tip of the light curing unit. A
DT_830C ,China _Digital Multimeter thermocouple (Figure1) was used to measure the temperature of each light source 
unit from a $1 \mathrm{~mm}$ distance during its operation. The temperature increases were evaluated every ten seconds with out stop during light curing for 40 seconds. Temperature measurements were repeated three times for every light source unit after a one hour standby period. The light intensity of each source unit was accepted as the manufacturer's specification. The room temperature was recorded to equal
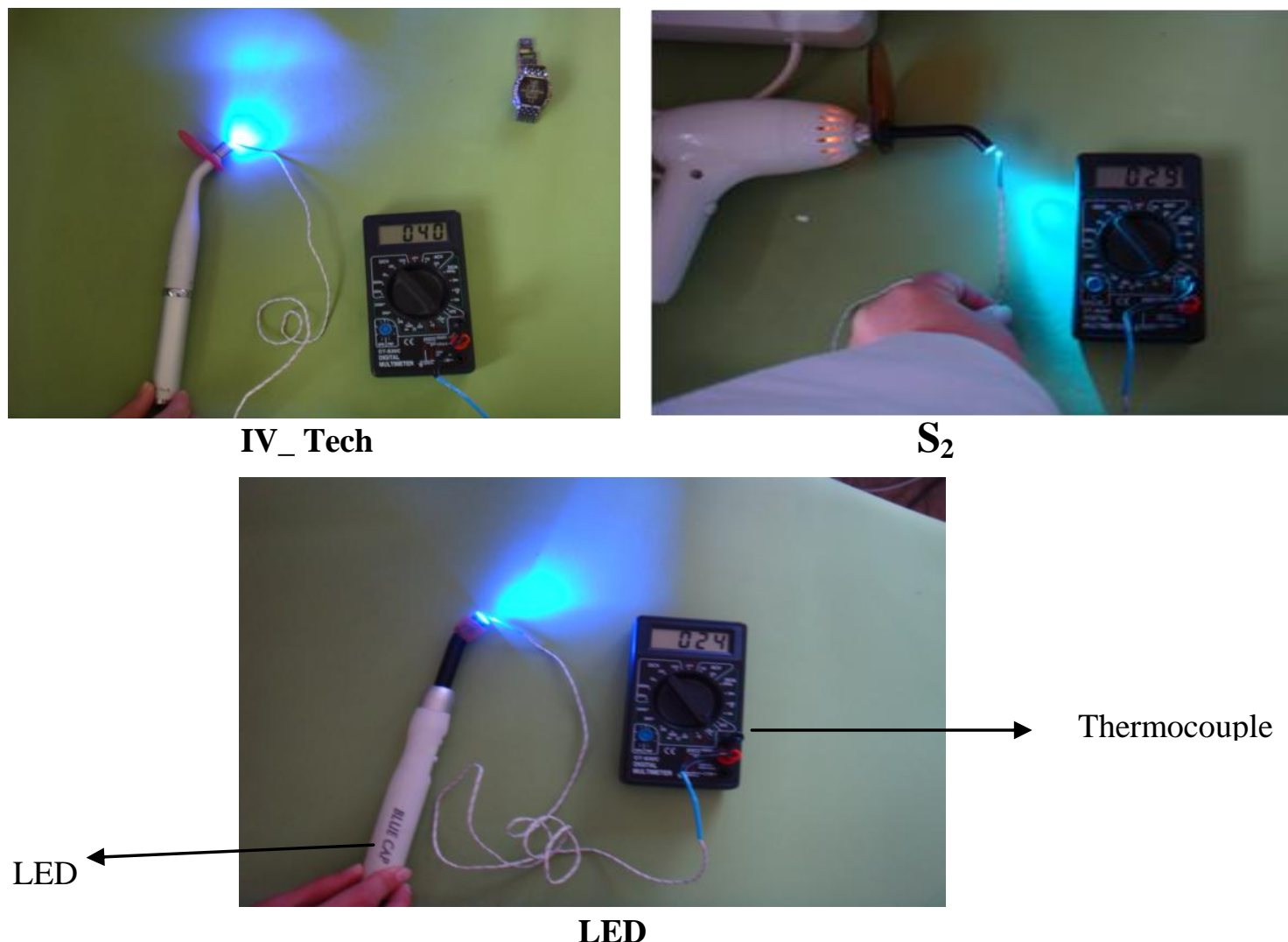

Figure(1) Light sources units and thermocouple

Table (2): Mean peak temperature rises (degrees Celsius) and standard deviations of the groups.

\begin{tabular}{|c|c|c|c|}
\hline $\begin{array}{c}\text { Time } \\
(\mathrm{sec})\end{array}$ & $\begin{array}{c}\text { Invisible technology } \\
\mathrm{IV} \_ \text {Tech }(\mathrm{M} \pm \mathrm{sd})\left({ }^{\circ} \mathrm{c}\right)\end{array}$ & $\begin{array}{c}\text { Special tungsten halogen } \mathrm{S}_{2} \\
(\mathrm{M} \pm \mathrm{sd})\left({ }^{\circ} \mathrm{c}\right)\end{array}$ & $\begin{array}{c}\text { Blue cap LED } \\
(\mathrm{M} \pm \mathrm{sd})\left({ }^{\circ} \mathrm{c}\right)\end{array}$ \\
\hline 10 & $32.6 \pm 0.5$ & $29 \pm 0.5$ & $24 \pm 0.5$ \\
\hline 20 & $33.6 \pm 0.5$ & $31.6 \pm .0 .5$ & $25.4 \pm 0.5$ \\
\hline 30 & $35.5 \pm 0.5$ & $33 \pm 0.5$ & $26.6 \pm 0.5$ \\
\hline 40 & $39.5 \pm 0.5$ & $34 \pm 0.5$ & $27.5 \pm 0.5$ \\
\hline
\end{tabular}




\section{RESULTS}

Statistical analysis was performed using Chi-Square test (Table3)for $\left(10^{\circ} \mathrm{c}\right),\left(20^{\circ} \mathrm{c}\right), \quad\left(30^{\circ} \mathrm{c}\right)$ and $\left(40^{\circ} \mathrm{c}\right)$ of all groups for comparisons among groups at the 0.05 level of significance. There were statistically no significant differences between light source units ( $p>.05$ ).

For all devices tested, an increase in irradiation time caused a proportionally elevation of the temperature(Figure2). Temperature rises were $\left(32.6^{\circ} \mathrm{C}\right),\left(33.6^{\circ} \mathrm{C}\right)$, $\left(35.5^{\circ} \mathrm{C}\right)$, and $\left(39.6^{\circ} \mathrm{C}\right)$ for each tested period at 10, 20, 30, and 40 seconds for the(IV_ Tech) light source unit. For the $\left(S_{2}\right)$ light source unit, these values were $\left(29^{\circ} \mathrm{C}\right),\left(31.6^{\circ} \mathrm{C}\right),\left(33^{\circ} \mathrm{C}\right)$, and $\left(34^{\circ} \mathrm{C}\right)$. The (LED) light source unit showed temperature rises of $\left(24^{\circ} \mathrm{C}\right),\left(25.4^{\circ} \mathrm{C}\right),\left(26.6^{\circ} \mathrm{C}\right)$, and $\left(27.5^{\circ} \mathrm{C}\right)$ during the same tested intervals. The least temperature increase was measured with the LED unit $\left(24^{\circ} \mathrm{C}\right)$ for each tested period. The (IV_ Tech) light source unit induced the highest temperature increase in all periods, and data was different than the other tested groups. Output values of all tested devices showed a temperature rise of more than $5.5^{\circ} \mathrm{C}$ except the Output values of Blue cap (LED) light source unit showed a temperature rise of less than $5.5^{\circ} \mathrm{C}$.

Table (3) Chi-Square Test Statistics for the means of the temperature rises at time $(10,20,30.40)$ sec of the groups.

\begin{tabular}{|c|c|c|c|c|}
\hline & Time(10)sec & Time(20)sec & Time(30)sec & Time(40)sec \\
\hline Chi-Square & .064 & .016 & .057 & .035 \\
\hline df & 5 & 5 & 6 & 5 \\
\hline $\begin{array}{c}\text { Asymp.Sig. } \\
\text { (P) }\end{array}$ & .999 & 1.000 & 1.111 & 1.000 \\
\hline
\end{tabular}

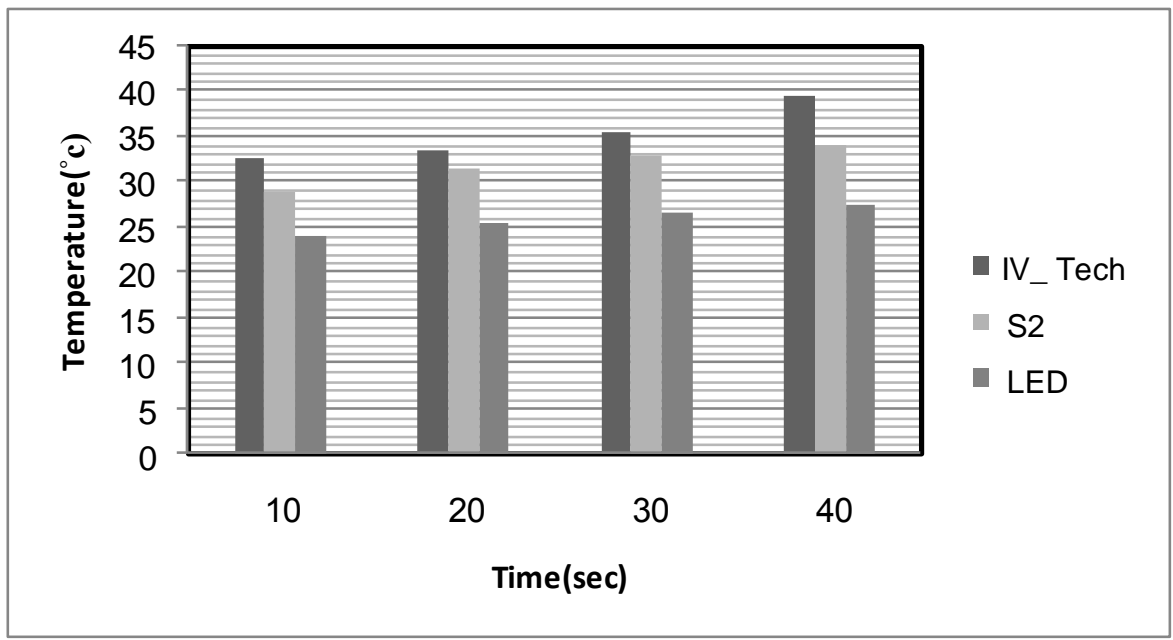

Figure(2):The relationship between the temperature and the time for three types of light sources units

\section{DISCUSSION}

This in vitro study measured temperature changes from the thermal emission by using three types of light sources unit which used in dentistry. The results obtained that the existence of a difference in temperature rise during the activation of three types of light sources units, due to 
the different levels of energy emitted by the units. For all light sources units, increasing irradiation time caused a proportionate elevation in temperature. The distance of the source tip was standardized for each light using an experimental model designed to fix the distance

$(1 \mathrm{~mm})$ between the thermocouple and the tip of the light source unit. The temperature rise increased with an increase in irradiation time; for all devices, increasing the irradiation time caused a proportionally elevated temperature.

The least temperature increase was measured with the LED light curing unit for each tested period. This study also showed most temperature increases were caused by the IV_ Tech light source unit for every tested period. Output values of all tested devices showed a temperature rise more than $5.5^{\circ} \mathrm{C}$ except the Output values of Blue cap (LED) light source unit showed a temperature rise of less than $5.5^{\circ} \mathrm{C}$.

\section{CONCLUSIONS}

Within the limitations of this study. The temperature increased with an increase in radiation time. The least temperature increase was measured with the Blue cap( LED ) light source unit $\left(24^{\circ} \mathrm{C}\right)$ for each tested period. The (IV_ Tech) light source unit induced a higher temperature increase in all periods, and data was different from the other groups .

Output values of all tested devices showed a temperature rise of more than $5.5^{\circ} \mathrm{C}$ except the Output values of Blue cap (LED) light source unit showed a temperature rise of less than $5.5^{\circ} \mathrm{C}$

\section{REFRENCES}

1. Preiskorn M. Zmuda S. Trykowski J.In vitro investigations of the heat transfer phenomena in human tooth. Acta of Bioengineering and Biomechanics: 2003; Vol.5,No.2.

2. Anthony HL., Tjan James R. Dunn .Temperature rise produced by various light generators through dentinal barriers. J prosthet Dent:1988;56,433-437.

3. Daniel Leonard, David Charlton, Howard Roberts, Mark Cohen. Polymerization efficiency of LED Curing lights. J Esthet and Res Dent :2002;14,286-295
4. Kleverlaan CJ, de Gee AJ. Curing efficiency and heat generation of various resin composites cured with high-intensity halogen lights. Eur J Oral Sci 2004; 112: 84-88.

5. Zach L, Cohen G. Pulp response to externally applied heat. Oral Surg Oral Med Oral Pathol 1965;19(4):515-530.

6. Yazici AR, Müftü A, Kufel G, Perry RD. Comparison of temperature changes in the pulp chamber induced by various light curing units, In vitro. Oper Dent 2006; 31-2:261-265.

7. Yap AUJ, Saw TY, Cao T, Ng MML. Composite cure and pulp-cell cytotoxicity associated with LED curing lights. Oper Dent 2004 Jan-Feb; 29: 92-99.

8. Hannig M, Bott B. In-vitro pulp chamber temperature rise during composite resin polymerization with various light-curing sources. Dent Mater 1999; 15(4): 27581.

9. Yap AUJ, Soh MS. Thermal emission by different light-curing units. Oper Dent 2003; 28(3):260-266.

10. Mc Cabe JF. Cure performance of lightactivated composites by differential thermal analysis (DTA).Dent Mater. $1985 ; 1: 231-234$.

11. Goodis HE, White JM, Gamm B, Watanabe L. Pulp chamber temperature changes with visible-light cured composites in vitro. Dent Mater. 1990; 6:99102.

12. Vaidyanathan J, Vaidyanathan TK. Computer-controlled differential calorimetric of dental composites. IEEE Trans Biomed Eng. 1991; 131:319-325.

13. Al-Qudah AA, Mitchell CA, Biagioni PA, Hussey PL. Thermo graphic investigation of contemporary resin-containing dental materials. J Dent. 2005; 33:593602.

14. Cacciafestaa V, Sfondrinib MF, Scribantec A, Boehmed A, Brinkmann PG. Effect of Light-tip Distance on the Shear Bond Strengths of Composite Resin. Angle Orthodont 2005; 75:386-391.

15. Bora B. Yildirim B. Ertan E. Seda U. Comparison of the Heat Generation of Light Curing Units. J. Dent. 2008: Volume 9, No. 2 . 